\title{
STATUS IDENTITAS ETNIK PADA MAHASISWA ETNIK SUNDA DAN CINA
}

\author{
Sanusi Soesanto \\ Universitas Kristen Maranatha
}

\begin{abstract}
This study aimed to get description of the Ethnic ldentity Status of Sundanese and Chinese ethnic background a Maranatha Christian University in Bandung. 49 students from Sundanese ethnicily and 98 students Chinese ethnicity were chosen as sample. Phinney's Ethic Identity Status interview was used to collect data while, Chi Quadrate was used to analyses the data. Result show that is a difference (Chi square X2 $=4.930 ; a=0.01$ ) between the ethric identity status of Sundanese and Chinese Ethnic Students. The two groups have a low percentage on Achieved Ethnic Identity. Sundanese students have higher percentage on Foreclosure Ethnic Identily (57.14\%) while students of Chinese ethricity have a higher percentage on Moratorium (Ethnic Identily Search $=58.16 \%$ ).
\end{abstract}

Key words: Ethnic Identity Status; Identity Achieved, Moratorium, Foreclosure, and Diffusion.

\section{Pengantar}

Indonesia adalah negara yang memiliki beraneka ragam etnik, budaya dan bahasa. Keanekaragaman ini terbentang dari Sabang sampai Merauke. Berbagai etnik yang ada telah tinggal selama berabad-abad di Indonesia dan telah mengalami berbagai era pemerintahan hingga saat ini. Masingmasing etnis memiliki adat, kebiasaan, dan bahasa sendiri yang sering tidak dimengerti oleh golongan etnis yang lain. Dalam kehidupan masyarakat yang multietnis sebagaimana layaknya negeri ini terdapat banyak sekall sumber-sumber nilai yang berbeda antara satu etnis dengan etnis lainnya.

Adanya perbedaan nilai pada setiap etnis karena adanya perbedaan faktor-faktor yang mengiringinya seperti letak geografis, adat-istiadat, agama, ekonomi, status sosial, dan keyakinan politik. Prosesnya pun tidak sederhana, karena unsur-unsur yang terlibat dalam pembentukan nilal df dalamnya tidak berdiri sendirl-sendiri. Faktor-faktor dari lingkungan, unsur-unsur kepribadian individu serta kondisl yang ada merupakan totalitas yang dapat mempengaruhi nilaj-nilai yang diyakini oleh etnis tertentu.

Salah satu gambaran dari keanekaragaman etnik adalah universitas. Universitas sebagai tempat berkumpul dan berinteraksi mahaslswa dari berbagai kelompok etnik. Fakultas Psikologi Universitas Kristen Maranatha di Bandung merupakan salah satu lembaga pendidikan yang memiliki mahasiswa dari berbagai kelompok etnik. Komposisi mahasiswa di Fakultas Psikologi Universitas Kristen Maranatha adalah $40 \%$ dari etnik Cina, $15 \%$ Sunda, $15 \%$ Jawa, $15 \%$ Batak, dan $15 \%$ dari etnik lainnya seperti Bali, Manado, Ambon, Papua, Minang, Dayak dan Aceh. Mahasiswa di Fakultas Psikologi Universitas Maranatha dengan mayoritas etnik Cina dan kelompok minoritas otnik Sunda berada pada masa remaja akhir. Pada masa ini, mahasiswa sedang mencari identitas diri yang dipengaruhi oleh etnik di mana remaja tersebut tumbuh dan dibesarkan.

Waterman (1982) memberi tuntutan teori bahwa pencarian identitas diri seseorang dipengaruhi oleh enam anteseden, yaitu (1) tingkat Identifikasi dri dengan orang tua sebelum dan selama periode remaja, 2) bentuk dan pola 
pengasuhan orang tua, (3) adanya model yang dirasakan sebagai figur penuh sukses dan hendak ditiru, (4) harapan sosial tentang identitas yang bisa dipilih dari apa yang ada di dalam keluarga, sekolah, teman akrab atau teman sepermainan, (5) luasnya kemungkinan remaja untuk diekspos dengan bebagai altematif identitas, dan (6) tingkat kepribadian sebelum remaja yang akan memberikan dasar-dasar yang tepat untuk membentuk suatu identitas yang menarik pehatiannya.

Berdasarkan anteseden-anteseden itu, remaja melakukan eksplorasl dan komltmen sehingga terbentuk identitas dengan pengaruh lingkungan sosial-budaya dimana remaja tersebut tumbuh dan berkembang. Oleh karena iu dilakukan penelitian pada remaja dengan etnik yang berbeda, yaitu suku bangsa Sunda dan Cina di Universitas Kristen Maranatha Bandung untu mengetahui status identitas.

\section{Dasar Teori}

\section{Status Identitas}

Pengertian identitas yang dikemukan oleh Erikson (1980) merujuk pada rasa kesadaran akan keunikan Individu, akan tetapi pada saat lain merujuk pada upaya tak sadar untuk pengalaman dan mengandung makna rasa setia kawan terhadap kelompok idealnya. Menurut Marcia (1980), identitas adalah struktur diri, suatu organisasl yang dinamis dari dorongan-dorongan, kemampuan-kemampuan, keyakinankeyakinan yang terstruktur dengan sendirlnya dalam diri remaja selama perkembangan remaja yang bersangkutan. Pembentukan identitas merupakan suatu sintesis dari persepsi dirl pada masa anak sampai remaja yang dilatarbelakangi oleh berbagai faktor hingga menjadi komitmen yang mantap pada seseorang. Pembentukan identitas terjadi pada saat remaja secara ideal membuat komitmen setelah melakukan eksplorasi tehadap berbagai kemungkinan altematif yang ada, sedangkan komitmen adalah titik akhlr dari proses eksplorasi itu (Archer, 1981).

Marcia (Adams, 1982) menerangkan bahwa status identitas yang dicapai pada masa remaja akhir adalah identity achievement, identity moratorium, identity foreclosure, dan identitydiffusion. Empat tipe dasar status identitas tersebut dimaksudkan untuk merepresentasikan integrasi dari proses pencarian/eksplorasi dan kekuatan komitmen dari remaja. Remaja dengan identity achievement telah mengalami proses eksplorasi dan telah berhasil mengatasi krisisnya sehingga mereka telah mampu membuat komitmen pad a pilihannya. Pada Remaja dengan identity moratorium menjalani eksplorasi secara intensif dengan aktif mencari alternatif-altematif. Kedatipun demikian, mereka belum memiliki komitmen atau kalaupun sudah ada bukan menspakan keputusan yang mantap. Mereka cenderung ragu-ragu dan menunda untuk mengambil keputusan apablla keadaan belum mendesak.

Remaja dengan identity foreclosure tidak pernah mengalami krisis atau tidak melakukan eksplorasi, tetapi mereka membuat komitmen. Komitmen mereka tentang vokasional atau pekerjaan dilakukan tanpa proses pencarian, melainkan pllihan pekerjaan tersebut seringkali merupakan warisan atau dibuat oleh orang tua atau orang dewasa lain. Bila mereka merasa tidak nyaman dengan keadaan yang tidak pasti maka mereka membuat keputusan tanpa pertimbangan yang matang. Identitydiffusion merepresentasikan seseorang yang tidak ada pencarian dan tidak ada kemauan maupun kemampuan untuk membuat komitmen yang mantap. Remaja dengan identity diffusion akan kehllangan rasa percaya diri dan bersembunyi di balik apatisme. Meskipun remaja dengan status identitas tidak mempertihatkan kecemasan, tetapi mereka sering apatis dan menjauhi aktivilas-aktivitas sosial dan pendidikan.

\section{Etnik Sunda dan Cina}

Bangsa Indonesia terdiri dari berbagai ragam etnik yang berbeda-beda, baik berasal dari pribumi maupun non-pribumi yang salah satunya adalah etnik Sunda dan Cina. Adapun latar belakang etnik Sunda pada seseorang diharapkan dapat menerima 
pandangan hidup yang benar dan salah, halal dan haram, hingga boleh dan bati sesuai didikan dari orang tua secara turunte murun. Masyarakat Sunda lebih mementingkan kerukunan sesuai dengan falsafah hid up yang dianutnya : silfh asih, silh asah dan sith asuh; saling mengasihi, saling menajamkan pikiran dan saling mengasuh di antara orang tiap orang (Ekadjati, 1991). Dalam kehidupan bermasyarakat, orangorang Sunda selalu berupaya untuk menjaga kerukunan dan menjauhi perbantahan. Menurut Zarkasih dan Yunus (1984), ungkapan Sunda yang menjadi peran dalam pola kehidupan masyarakat Sunda adalah kudu hade gogog, hade togo yang berarti harus baik budi bahasa dan baiktingkah laku. Makna yang terkandung dalam ungkapan ini adalah memberikan nasihat atau anjuran agar orang Sunda senatiasa memperlihatkan perangai yang ramah dan kelakuan yang sopan. Ungkapan ini biasanya digunakan orang-orang dalam mendidik anak-anak mereka agar senantiasa memelihara keindahan dalam berbicara dan bersikap. Selaln itu, adanya ungkapan bisi aya $t i$ cai ti geusan mandi artinya segala sesuatu harus dipertlmbangkan agar pihak lain tidak tersinggung. Makna yang terkandung agar orang $s u n d a$ senantías a mempertimbangkan segala sesuatu yang akan dilakukannya. Hal ini dilakukan untuk menghindari perpecahan dan permusuhan yang tidak diinginkan.

Hal ini berbeda dengan etnik Cina, sesual dengan ajaran Kong Fu Tse yang merupakan falsafah yang berkaltan untuk hidup secara balk. Ajaran Kong Fu Tse mengatakan jikalau orang masih belum mengetahul hal hidup, bagaimana orang dapat mengetahui hal mati. Hal ini bermakna mengenal cara hidup d dunia fana ini dan bukan mengenai hidup di alam baka. Falsafah hubungan antara anak dan orang tua terutama mengenai kewajban kebaktian anak terhadap orang tuanya. Konsep kebaktian orang Cina ditafsirkan dalam pemujaan ieluhur dengan memelihara abu dalam rumah, ayah menjadi pemuka upacara. Kewajiban ini turun kepada anak laki-laki yang sulung dan begitu seterusnya.
Anak perempuan tidak disebutkan dalam pemujaan leluhur, karena anak perempuan sesudah menikah mengikuti suaminya dan dengan begitu yang turut diurusnya adalah pemujaan leluhur dari pihak suaminya. Selain itu, anak laki-laki dibutuhkan untuk melanjutkan She-nya (nama keluarga) untuk menggantikan ayahnya bila kelak harus merawat abu leluhurnya. Berbakti akan orang tua memang sesuatu hal yang wajar, tetapi pada orang Cina berbakti itu mempunyai atau mendapatkan arti keramat.

\section{Metode Penelltlan}

Penelitian ini merupakan penelitian surve. Penelitian Inl bertujuan untuk mengetahui deskripsi status identitas etnik pada etnik Sunda dan Cina..

Variabel penelitian ini adalah status identitas etnik dengan membandingkan dua etnik yang berbeda yaitu etnlk Sunda dan Cina.

Pengambilan data dilakukan dengan menyebarkan kuesloner status identitas etnik pada mahasiswa Fakuitas Psikologi Universitas Kristen Maranatha angkatan 2002 yang beretnik Sunda dan Cina pada bulan Maret 2004. Pengisian kuesioner status identitas elnik membutuhkan waktu 30 menit yang dilakukan secara klasikal. Subyek penelitian adalah mahasiswa Fakultas Psikologi Univeritas Kristen Maranatha angkatan 2002 dari dua kelompok etnik yang berbeda. Subjek dari kelompok etnik Sunda sebanyak 49 mahasiswa dan kelompok etnik Cina sebanyak 98 mahasiswa. Jumlah sampel saat pengambilan data dari 2 kelompok etnik yang berbeda ini berdasarkan rasio 1: 2 karena jumlah mahasiswa etnik Cina dua kali lebih ban yak dari etrik Sunda.

Alat ukur status identitas etnik dari Phinney yang terdiri dari $\mathbf{2 0}$ aitem pernyataan yang memiliki validitas dengan koefisien korelasi yang berkisar antara 0.42-0.87 dan koefisien rellabilitas dari Affa Cronbach sebesar 0.82 .

Jenis penelitian yang digunakan adalah komparatif dengan membandingkan dua kelompok etnik yang berbeda yaitu etnik 
Sunda dan Cina. Subyek dari dua kelompok etnik yang berbeda diberikan kuesioner status identitas etnik dari Phinney. Selanjutnya, hasil penelitian diolah dengan menggunakan metode analisis Chi Square sehingga didapatkan gambaran dari penelitian ini.

\section{Hasil Penelitian}

Berdasarkan hasil penelitian dapat diketahui bahwa terdapat pebedaan status identitas etnik pada mahasiswa etnik Sunda den Cina di Fakultas Psikologi UK Maranatha dengan Chi Square sebesar 4.930 dan á = 0.01 . Adapun gambaran status identitas etnik pada mahasiswa etnik Sunda dan Cina adalah sebagai berikut.

Tabel 1.

Gambaran Status Identitas Etnik Pada Mahasiswa Etnik Sunda dan Cina

\begin{tabular}{|l|c|c|c|c|}
\hline Etnis & Foreclosure & Moratorium & Achieved & Frequency \\
\hline Etnis Sunda & $57.14 \%$ & $38.78 \%$ & $4.08 \%$ & $100 \%$ \\
\hline Etnis Cina & $38.77 \%$ & $58.16 \%$ & $3.07 \%$ & $100 \%$ \\
\hline
\end{tabular}

\section{Pembahasan}

Berdasarkan hasil penelitian diketahul adanya perbedaan antara status identitas etnik pada etnik Sunda dan Cina. Marcia (Adams, 1982) menerangkan bahwa status identitas yang dicapal pada masa remaja akhir adalah Identity achievement, Identity Moratorium, identily foroclosure, dan Identity diffusion. Empat tipe dasar status Identitas tersebut dimaksudkan untuk mempresentasikan integrasi dari proses pencarian/eksplorasl dan kekuatan komitmen dari remaja. Perbedaan status identitas etnik dapat terjadl karena dlpengaruhi oleh beberapa anteseden, terutama dalam kaitannya dengan budaya dalam keluarga, seperti (1) tingkat identifikasi diri dengan orang tua sebelum dan selama periode remaja, (2) bentuk dan pola pengasuhan orang tua, (3) adanya model yang dirasakan sebagal figur penuh sukses dan hendak ditiru, (4) harapan sosial tentang identitas yang bisa dipilih dari apa yang ada didalam keluargan (Waterman, 1982).

Perbedaan tampak pada prosentase identily foreclosure yang cukup tinggi pada etnik Sunda (57, 14\%) dibandingkan dengan etnlk Cina dan sebaliknya, prosentase identity moratorium yang cukup tinggi pada etnik Cina $(58,16 \%)$ dibandingkan etnik Sunda. Hal inl berarti status identitas pada mahasiswa etnik sunda cenderung melakukan komitmen tanpa melakukan eksplorasi secara mendalam berkaitan dengan dorongan-dorongan, kemampuankemampuan, dan keyakinan-keyakinan yang terstruktur dalam diri mahasiswa selama masa perkembangan yang bersangkutan. Menurut Marcia (1980), komitmen mereka dilakukan tanpa proses pencarian, melainkan pilihan seringkali merupakan warisan atau dibuat oleh orang tua atau orang dewasa lain. Berhubungan mereka merasa tidak nyaman dengan keadaaan yang tidak pasti maka mereka membuat keputusan tanpa pertimbangan yang matang.

Sebaliknya mahasiswa etnik Cina cenderung melakukan eksplorasi secara terus menerus untuk mengetahui dorongandorongan, kemampuan-kemampuan, dan keyakinan-keyakinannya. Kendatipun demikian, mereka belum memiliki komitmen atau kalaupun sudah ada bukan merupakan keputusan yang mantap. Mereka cenderung 
ragu-ragu dan menunda untuk mengambil keputusan apabila keadaan belum mendesak (Marcia, 1980).

Namun pada identity achievement pada mahasiswa etrik Sunda dan Cina tampaknya hanya sedikit mahasiswa yang dapat mencapainya dan tidak jauh berbeda antara kedua etrik tersebut. Hal ini berarti bahwa hanya sebagian kecii mahasiswa dari kedua etnik tersebut telah melakukan eksplorasi hingga pada akhirnya menetapkan komitmen berkaitan dengan tujuannya di masa depan.

\section{Penutup}

Penelitian kuantitatif dengan metode survei pada sejumlah mahasiswa yang memiliki latar belakang berbeda ini diharapkan dapat memberikan sumbangan yang cukup berarti bagi masyarakat dalam menambah informasi tentang status identitas etnik pada mahasiswa dengan latar belakang yang berbeda. Namun demikian perlu adanya pertimbangan yang mendalam berkaitan dengan iatar belakang mahasiswa etnik Cina yang cenderung heterogen karena merupakan pendatang untuk mengikuti studi di Fakultas Psikologi UK. Maranatha dibandingkan dengan mahasiswa etnik Sunda yang merupakan penduduk asli Jawa Ba rat.

Dengan kata lain, hasil penelitian in! tidak dimaksudkan untuk dapat dijadikan landasan untuk mengeneraiisasikan suatu temuan, melainkan ditujukan untuk memberikan informasi tambahan mengenai status identitas etrik sebagai penelitian psikoiogi lintas budaya.

Penelitian ini memiliki keterbatasan berkaitan dengan status identitas etrik karena dilakukan hanya pada mahasiswa Fakultas Psikologi UK Maranatha. Selain itu, kurang jelasnya sasaran dari status identitas yang akan diteliti berkaitan dengan bidang pendidikan ataupun pekerjaan yang akan dilakukan pada masa mendatang. Keterbatasan dalam penelitian ini diharapkan dapat mengugah peneliti tainnya yang berminat untuk melakukan penelitian daiam popuiasi yang lebih luas dan jelasnya sasaran statu identitas etrik yang akan diteliti.

Penelitian ini dibatasi pada mahasiswa etnik Sunda dan Cina di Fakultas Psikologi UK Maranatha. Hal ini membuat kurang homogen pada sampel mahasiswa etrik Cina karena merupakan pendatang dari berbagal daerah sehingga status identitas etnik banyak dipengaruhi oleh budaya dimana mereka dibesarkan sebelumnya. Penelitian seianjutnya lebih difokuskan pada etrik Cina di Jawa Barat saja ataupun etrik lainnya, seperti Jawa, Batakataupun Papua.

Status Identitas etrik yang dirasakan kurang jelas sasarannya yaitu bidang pendidikan ataukah pekerjaan (vokasional), seuaiknya penelitian lanjutan dengan tegas menetapkan sasarannya yaitu hanya bidang pendidikan atau pekerjaan saja.

\section{Daftar Pustaka}

Adams, G. R \& Fitch, S. A. 1982. Ego stage and identity status development : A cross-sequential analysis. Journal of Personality and Social Psychology, 43, 574-583.

Archer, S. L. 1981. Ego identity development among early and middio adolescents. Paper presented at the meeting of the Eastern Psychological Association. New Yok The Eastern Psychological Association

Ekadjati, E.S. 1987. Pandangan hidup Sunda seperti tercermin dalam tradisi //san dan sastra Sunda. Bandung: Proyek Peneitian dan Pengkajian Budaya Sunda.

Ekadjati, E.S. 1991. Masyarakat Sunda. Bandung: Giri Mukti Pasaka.

Erikson, $E$ H. 1980. Identity and the Lifecycle: A reissure. New York : Norton. 
Hidajat, Z.M.. 1993. Masyarakat dan Kebudayaan Cina Indonesia. Bandung: Tarsito.

Marcia, J.E. 1980. Identity in adolescence. In J. Adelson (Ed.), Handbook of Adolescence Psychology. New Yark :Wiley.
Waterman, A.S. 1982. Identity development from adolescence to adulthood: An extension of theory and a review of research. Developmental Psychology, 18, 342358.

Zarkasih, R. dan Yunus, H.A. 1984. Ungkapan Tradisional Jawa Barat. Jakarta: Departemen Pendidikan dan Kebudyaan. 